\title{
BRAZILIAN CONSENSUS MEETING ON PEDIATRIC HEMATOPOIETIC STEM CELL TRANSPLANTATION FOR ACQUIRED APLASTIC ANEMIA AND INHERITED BONE MARROW FAILURE SYNDROMES
}

\author{
Luiz Guilherme Darrigo Junior ${ }^{1}$, Gisele Loth ${ }^{2,3}$, Phillip Scheinberg ${ }^{4}$, Elias Hallack Atta ${ }^{5}$, \\ and Carmem Bonfim ,3,6

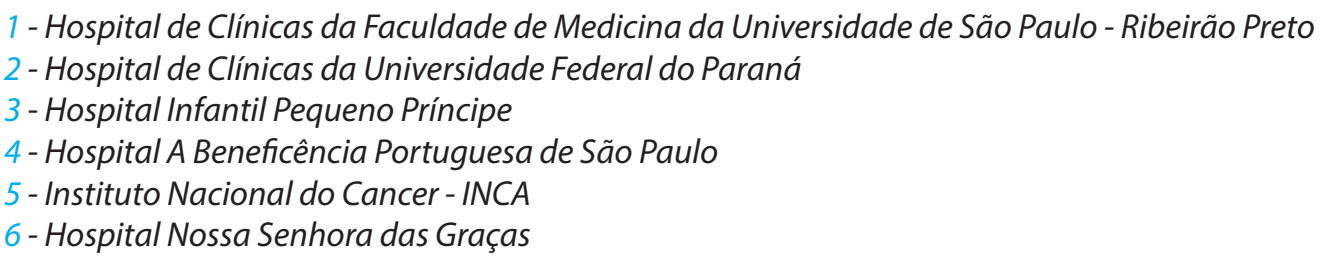

Correspondence to: Luiz Guilherme Darrigo Junio - darrigo.jr@gmail.com

\section{INTRODUCTION}

Aplastic anemia $(A A)$ is characterized by bone marrow failure associated with pancytopenia and bone marrow hypoplasia/aplasia, without excessive blasts, neoplastic infiltration, or fibrosis. AA can be hereditary or acquired, an important distinction given that hereditary presentations do not respond to immunosuppression'. Most cases are acquired where an etiologic trigger cannot be identified, in which autoimmune pathophysiology is inferred ${ }^{2}$.

Acquired $A A$ is a rare disease with an estimated incidence of 2 to 3 cases per million in the Western world and 1,64 cases per million in Latin America. This disease is even rarer in the population under ten years, with an incidence rate of 0,92 cases per million inhabitants/year. There are two incidence peaks, the highest around 20-30 years and the second after 60 years $^{3}$.

\section{ETIOLOGY AND PATHOPHYSIOLOGY}

The rarity of the disease is probably explained by the need for a combination of factors for its development. The etiology involves predisposing characteristics, exposure to specific events, and individual differences in the immune response. Unfortunately, the way each one of these factors contributes to disease mechanisms has not yet been completely clarified. Currently, about 70 to $80 \%$ of cases are considered idiopathic. However, exposure to certain drugs, infections, radiation, pregnancy, and rheumatologic diseases may be involved in its etiology, either by direct toxicity to the hematopoietic stem cell or by an immune mechanism ${ }^{4}$.

In most cases, AA behaves like an immune-mediated disease. Initially, occurs an activation and expansion of oligoclonal cytotoxic T cells. Then, the release of hematopoiesis-suppressing cytokines: interferon- $\gamma($ IFN- $\gamma)$, tumor necrosis factor- $a($ TNF- $\alpha)$, and interleukin-6 (IL-6), which cause DNA damage and consequent apoptosis of bone marrow CD34+ stem cells. In vitro studies have already proven these mechanisms. However, it is still unknown what the initial trigger for $T$ cell activation is, nor how the disruptive event that leads to loss of immune tolerance occurs $^{2,5}$.

The response to immunosuppressive therapy supports this immune hypothesis for the pathophysiology of AA. However, a small part of the cases may have other mechanisms involved. About a third of patients have shortened leukocyte telomeres, which may be due to mutations in the telomerase complex. These mutations reduce the enzyme activity, causing progressive erosion of telomeres and a deficiency in the proliferative capacity of hematopoietic progenitor cells ${ }^{2,3}$.

Normal hematopoiesis also involves a complex relationship between progenitor cells and the bone marrow microenvironment, which is nec- 
essary to regulate various stages of cell proliferation and differentiation. In AA, the microenvironment can also be affected, preventing the proliferation of stem cells, even if transplanted from a healthy donor ${ }^{6,7}$.

The pathophysiology of AA, therefore, suggests two possibilities for treatment: Hematopoietic stem cell transplantation (HSCT), which replaces deficient hematopoietic stem cells (HSC) with normal progenitors; and suppression of the immune process that causes damage to hematopoiesis'.
In face suspicion of aplastic anemia, the diagnosis of acquired AA must be differentiated from inherited bone marrow failure syndromes (IBMFS) since the management and treatment are different ${ }^{8}$.

\section{DIAGNOSIS AND CLASSIFICATION}

Considering the need for proper investigation for the differential diagnosis, including personal and family history, exposure to toxins and infectious agents, physical examination focused on malformations and other somatic abnormalities characterizing constitutional marrow failure syndromes, in addition to careful clinical evaluation, the following tests are recommended (table1):

TABLE 1. Diagnostic tests

\begin{tabular}{|c|c|}
\hline Mandatory tests for diagnosis & $\begin{array}{l}\text { Ideal investigation for differential diagnosis with } \\
\text { constitutional syndromes }\end{array}$ \\
\hline $\begin{array}{c}\text { - Complete blood count } \\
\text { - Reticulocyte count } \\
\text { - Liver function tests } \\
\text { - Testes de função hepática } \\
\text { - Serology / PCR for viral hepatitis } \\
\text { - Myelogram } \\
\text { - Cytogenetics of bone marrow } \\
\text { - Immunophenotyping of bone barrow } \\
\text { - Bone marrow biopsy } \\
\text { - Peripherical blood flow cytometry for paroxysmal } \\
\text { nocturnal hemoglobinuria } \\
\text { - Screening for autoantibodies } \\
\text { - Dosage of vitamin B12 and folate }\end{array}$ & $\begin{array}{c}\text { - Chromosomal fragility test (mitomycin or } \\
\text { diepoxybutane) } \\
\text { - Fecal elastase and pancreatic lipase } \\
\text { - Fibrinogen and serum ferritin } \\
\text { - Telomeric length } \\
\text { mutations: } \\
\text { - Next-Generation Sequencing (NGS) panels to identify cryptic } \\
\text { TERC and TERT mutation analysis } \\
\text { TNF2, NHP2, NOP10, DKC1, and cMPL mutation analysis } \\
\text { Shwachman-Diamond Syndrome mutation analysis } \\
\text { Blackfan-Diamond Syndrome mutation analysis }\end{array}$ \\
\hline
\end{tabular}

After the diagnosis, the classification of disease must be made based on the abnormalities present in the bone marrow and peripheral blood, as demonstrated in table 2 .

TABLE 2. Classification of AA based on the severity 5

\begin{tabular}{|c|c|c|}
\hline $\begin{array}{c}\text { Moderate or Non-severe Aplastic } \\
\text { Anemia (NSAA) }\end{array}$ & Severe Aplastic Anemia (SAA) & Very Severe Aplastic Anemia (VSAA) \\
\hline $\begin{array}{l}\text { - Hematopoietic marrow cellularity } \\
\qquad<30 \% \\
\text { - Neutrophil }>500 / \mu \mathrm{l} \text { but }<1000 / \mu \mathrm{l} \\
\text { - Lack of criteria for severe or very } \\
\text { severe }\end{array}$ & $\begin{array}{l}\text { - Hematopoietic marrow cellularity } \\
\qquad 30 \% \\
\text { - At least two of the following } \\
\text { conditions: } \\
\text { Neutrophil }<500 / \mu \mathrm{l} \\
\text { Platelets }<20.000 / \mu \mathrm{l} \\
\text { Reticulocytes }<20.000 / \mu \mathrm{l}\end{array}$ & - Like severe but with neutrophils $<200 / \mu l$ \\
\hline
\end{tabular}




\section{FIRST-LINE TREATMENT OF ACQUIRED SAA}

Nowadays, HSCT and IST are considered acceptable treatment options for children with acquired AA. The current guidelines recommend that patients younger than 40 years with an HLA-identical related donor undergo HSCT as their first-line treatment ${ }^{9}$. Matched unrelated donor (MUD) HSCT is considered an option for first-line therapy if performed in less than 2-3 months. Otherwise, immunosuppression should be initiated ${ }^{10}$. Thus, HLA typing for the patient and family should be immediately performed for any patient with newly diagnosed SAA who is a candidate for HSCT. The source of HSC for HSCT in SAA should always be bone marrow. An EBMT registry study with 1886 patients with SAA who underwent HLA-identical related HSCT observed an overall survival (OS) advantage for patients who received bone marrow compared to peripheral blood in all age groups: 1-19 years $(90 \%$ versus $76 \%, \mathrm{P}<0.00001){ }^{11}$. Rabbit ATG should always be used in the conditioning regime for related HSCT. A CIBMTR registry study demonstrated a protective effect of rabbit ATG against acute and chronic GVHD in related HSCT: $17 \%$ versus $6 \%(P<0.001)$ and $20 \%$ versus $9 \%(P<0.001)$, respectivel ${ }^{12}$. In unrelated HSCT, rabbit ATG protected against acute GVHD ( $42 \%$ versus $23 \%, \mathrm{P}<0.001)$ and was independently associated with better OS $(83 \%$ versus $75 \%, P=0.02)^{12}$. The conditioning regime in SAA must be non-myeloablative due to the absence of malignant cells, therefore preserving fertility in young patients and reducing the long-term sequelae after HSCT.

Currently, recommended conditioning regimens for related HSCT is CY $200 \mathrm{mg} / \mathrm{kg}$ + rabbit ATG $5-7.5$ $\mathrm{mg} / \mathrm{kg}$ while the recommended conditioning regimens for unrelated HSCT are Fludarabine $120 \mathrm{mg} / \mathrm{m}^{2}$ + CY $120 \mathrm{mg} / \mathrm{kg}$ + rabbit ATG $5-7.5 \mathrm{mg} / \mathrm{kg} \pm$ total body irradiation (TBI) 200 cGy (10). The addition of $\mathrm{TBI}$ at a dose of $200 \mathrm{cGy}$ reduces the incidence of primary failure, especially in adult and/or polytransfused patients ${ }^{13}$. The ideal immunosuppression regimen after HSCT in SAA consists of a combination of a calcineurin inhibitor (tacrolimus or cyclosporine A) with methotrexate ${ }^{14}$. The calcineurin inhibitor must be started on day -1 and must be maintained for at least one year after HSCT with a slow withdrawal afterward. Methotrexate should be used on the shortcourse regimen $\left(15 \mathrm{mg} / \mathrm{m}^{2}\right.$ on day +1 and $10 \mathrm{mg} / \mathrm{m}^{2}$ on day +3 , day +6 , and day +11 ).

Those not eligible for upfront transplant due to a lack of an HLA-matched donor should receive treatment with horse anti-thymocyte globulin (ATG) and cyclosporine $(C S A)^{9}$. Due to the unavailability of horse ATG in Brazil, rabbit ATG is used for first-line treatment in association with CSA, despite the lower response rate observed with this ATG preparation compared with horse $\mathrm{ATG}^{9,15}$. A recent study showed that eltrombopag added to horse ATG-based IST did not improve outcomes in children with $S A A^{16}$. The combination of rabbit ATG-based IST and eltrombopag for the first-line treatment of acquired SAA is still unknown.

\section{SECOND-LINE TREATMENT OF ACQUIRED SAA}

Patients who do not respond to first-line immunosuppressive treatment must undergo bone marrow reassessment to exclude clonal evolution. An HLA MUD should be preferred at this time using the conditioning regimen described before.

Although early studies on UCBT in patients with acquired AA showed limited success, new studies have shown promising results. Kudo et al, demonstrated the excellent OS in patients treated with the conditioning regimen comprising fludarabine, cyclophosphamide or melphalan, and low dose irradiation without anti-thymocyte globulin ${ }^{17}$. Similar results were demonstrated by the French group in a prospective study using conditioning with FLU, CY and 2 Gy of TBI with ATG; this group reported a 2-year OS rate of $81 \%$ and engraftment of $88 \%{ }^{18}$.but results from previous studies are not encouraging. We conducted a prospective nationwide phase 2 study to assess unrelated cord blood (CB Considering this data, we believe that UCB transplantation can be a treatment option for children who lack an MRD, MUD or emergency cases.

Haploidentical HSCT is another promising treatment option for patients with acquired AA who failed IST or even patients who failed a previous $\mathrm{HSCT}^{19}$. The choice between a mismatched unrelated donor or a haploidentical related donor must be made individually. This decision should be based upon the urgency of the transplant, neutrophil count, age of the recipient, the donor's characteristics (age, gender, and $A B O / C M V$ agreement), and the presence of donor-specific antibodies against HLA (DSA).

Based on national experience, the recommended conditioning regimen for haploidentical HSCT consists in the association of:

Flu 150 mg/m² + CY 29 mg/kg + TBI 400 cGy single dose. The use of increased doses of TBI was associated with a reduction in the primary graft rejection rate, $27 \%$ versus $7 \%(P=0.02)$, and a higher 2 -year event-free survival, $88 \%$ versus $60 \%(P=0.01)$. The 
role of rabbit ATG in conditioning for haploidentical HSCT remains controversial. It can be considered mainly for the treatment of naïve patients or those who have not received ATG during immunosuppressive treatment ${ }^{20}$.

The source of HSC must be the bone marrow, and GVHD prophylaxis consists of the association of $\mathrm{CY}$ $50 \mathrm{mg} / \mathrm{kg} /$ day on days +3 and +4 , mycophenolate mofetil $45 \mathrm{mg} / \mathrm{kg} /$ day from day +5 to +35 , and calcineurin inhibitor from day +5 to +365 with slow withdrawal after this period ${ }^{20}$.

Although promising, haploidentical transplantation is still not recommended in the upfront treatment of $A A$ until the results of prospective studies (NCT02833805). However, in some select cases in the pediatric setting, upfront haploidentical BMT may be considered for patients with zero neutrophils or very severe aplastic anemia and life-threatening infections in centers of expertise.

\section{INHERITED BONE MARROW FAILURE SYNDROMES}

Inherited Bone Marrow Failure Syndromes (IBMFS) constitute a heterogeneous group of genetic disorders characterized by the inadequate production of one or more hematopoietic lineages leading to the development of cytopenias ${ }^{21,22}$. Distinct biological mechanisms underlie the pathophysiology in IBMFS, such as repair pathways in Fanconi anemia (FA), telomere maintenance in dyskeratosis congenita (DKC), and ribosomopathy in Shwachman Diamond syndrome (SDS) and Diamond Blackfan anemia (DBA) ${ }^{23}$. These disorders are generally associated with the presence of congenital malformations and an increased risk of cancer, especially hematological and gynecological, as well as squamous cell carcinomas ${ }^{24}$. Although the diagnosis usually occurs in childhood, adults with a history suggestive of a hereditary bone marrow failure syndrome should be investigated ${ }^{22}$. It is essential to highlight that these patients must be monitored throughout their lives, given the risk of developing non-hematopoietic neoplasias, which have a better prognosis if detected early ${ }^{25}$.

\section{FANCONI ANEMIA}

Fanconi Anemia (FA) is rare, with a prevalence of 1 in every 100,000 births, usually inherited as an autosomal recessive disease. It is characterized by progressive bone marrow failure, congenital malformations, and increased risk of myelodysplasia and acute myeloid leukemia, as well as solid tumors, particularly squamous or epithelial cell carcinomas. Although congenital abnormalities are frequent, up to $30 \%$ of FA patients may not present apparent somatic abnormalities. However, bone marrow failure will develop in approximately $90 \%$ up to 40 years of age, the majority at the end of the first decade $e^{21,26}$.

The disease results from functional impairment of genes involved in the DNA repair pathway, making these patients highly susceptible to severe damage from ionizing radiation and chemotherapy, making HSCT particularly challenging. The diagnosis is based on the chromosomal breakage tests with diepoxybutane (DEB) and mitomycin. To date, 22 genes involved in the pathogenesis of the disease have been identified, with the FANCA mutation being the most prevalent ${ }^{27}$.

For patients in the aplastic phase, treatment involves transfusions of blood components and androgens, while HSCT is considered the only curative treatment. Nevertheless, due to genomic instability, transplant strategies need to be modified to decrease transplant-related toxicity and mortality. The 5-year survival after a transplant from a compatible related donor is around $90 \%$, and very similar for alternative donors ${ }^{28,29}$.

\section{BLACKFAN DIAMOND SYNDROME}

Blackfan Diamond Anemia (BDA) is caused by a defect in erythropoietic progenitors, resulting in severe anemia with very early onset, most commonly before the first year of life. It has an incidence of 7 in every 1 million live births. It is caused by mutations in ribosomal protein genes, the most common being RPS19, or in non-ribosomal genes, such as GATA1, $\mathrm{TSR} 2, \mathrm{ADA} 2$, and $\mathrm{EPO}^{30}$.

About $50 \%$ of patients have associated congenital abnormalities, the most common being craniofacial, skeletal, genitourinary, cardiac, and upper limbs. There is also a predisposition to hematologic malignancies, such as myelodysplasia and acute myeloid leukemia (AML), and solid tumors, such as colon carcinoma and osteosarcoma.

The first line of treatment is corticosteroid therapy, but although $80 \%$ have an initial response, only $20 \%$ of patients achieve complete and lasting remission without corticosteroid dependence. HSCT is potentially curative and is indicated for non-responders to corticosteroids, who need high doses to obtain a satisfactory response, or those who evolve with aplasia in other series or myelodysplasia/AML ${ }^{31,32}$. Best results are achieved when patients are transplanted young with a matched related or unrelated donor following a myeloablative regimen ${ }^{32,33}$. 


\section{TELOMERE DISEASES / DYSKERATOSIS CONGENITAL (DC)}

Telomere disease is a group of disorders with a broad spectrum of manifestations caused by a structural defect and repair of telomeres. Hematological manifestations are widespread and include bone marrow aplasia, cytopenia of at least one lineage, in addition to myelodysplasia and acute myeloid leukemia ${ }^{34}$

The classic form of telomere disease is dyskeratosis congenita, which is characterized by a triad of manifestations that include reticular pigmentation of the skin, oral leukoplakia, and dystrophic nails. However, the range of manifestations associated with the mutations described in telomere disease is extensive, from patients with only hematological involvement to complex syndromes such as Hoyeraal-Hreidarsson Syndrome, Revesz Syndrome, and Coats plus Syndrome. The onset of manifestations can also occur from infancy to the fifth decade of life ${ }^{34}$.

The pathophysiology of the disease is linked to mutations such as DKC1, TERC, TERT, NOP10, NHP2, TCAB1, NAF1, PARN, and TINF2, which affect the transcription of proteins linked to telomere maintenance. Failure in this maintenance leads to progressive telomere shortening, with consequent cessation of cell replication and senescence. The inheritance pattern can be X-linked or autosomal dominant, with variable penetrance ${ }^{35}$. Although results have improved in the past decade due to reduced-intensity regimens, long-term survival is still poor because of disease progression (pulmonary and liver fibrosis and hepatopulmonary syndrome) ${ }^{36,37}$.

\section{CONGENITAL AMEGAKARYOCYTIC THROMBOCYTOPENIC}

Congenital amegakaryocytic thrombocytopenia (CAMT) is a rare marrow failure syndrome, characterized by thrombocytopenia from birth, with progression to aplasia (91\% at 13 years of age) or acute myeloid leukemia ( $55 \%$ at 17 years of age) ${ }^{22}$. Patients with this disease do not have typical physical characteristics, except for the signs of bleeding associated with thrombocytopenia.

In most cases, the disease is associated with an autosomal recessive mutation in the MPL gene, which encodes the thrombopoietin receptor ${ }^{38}$. Although there is a possibility of response to the use of androgens, a definitive cure can only be achieved with hematopoietic stem cell transplantation ${ }^{39}$.

\section{SHWACHMAN DIAMOND SYNDROME}

Shwachman Diamond Syndrome accounts for up to a quarter of congenital neutropenia cases. It is characterized by bone marrow failure, exocrine pancreatic dysfunction, and predisposition to myelodysplasia and acute myeloid leukemia. The patient usually presents with moderate and intermittent neutropenia, mild to moderate thrombocytopenia and anemia and increased fetal hemoglobin. Diarrhea is expected, with increased fat and decreased fecal elastase $^{40}$. The syndrome may be associated with malformations such as metaphyseal dysplasia and narrow thorax, cutaneous manifestations such as eczema and ichthyosis, in addition to psychomotor and growth retardation. The disease may go clinically unnoticed until malignant transformation, which occurs in up to $36 \%$ of patients ${ }^{41}$.

Almost $90 \%$ of patients have an autosomal recessive mutation in the SBDS gene, which encodes a protein involved in ribosomal maturation. However, mutations in SRP54, DNAJC21, and EFL1 can have a similar clinical presentation ${ }^{42}$. HSCT is indicated for patients that develop severe cytopenias and clonal evolution. Two recent publications from Europe and the USA have shown a 5 -year OS of $70 \%$ for pts with marrow failure (using reduced-intensity regimens) and a dismal outcome for those with MDS or AML ${ }^{41,43}$.

\section{GENERAL RECOMMENDATIONS}

Donor selection: All siblings should be tested for IBMFS before being considered potential donors for $\mathrm{HSCT}^{44}$.

HLA Compatibility: The ideal unrelated donor must be HLA identical in high resolution typing for the HLA-A, -B, -C, -DRB1, and -DQB1 locus, that is, 10:10 compatibility. Donors with one or more allelic incompatibility are at increased risk of primary graft failure, GVHD, and transplant-related mortality ${ }^{45}$. We recommend testing DP locus as incompatibilities in DPB1 are associated with an increased risk of GVHD and transplant-related mortality ${ }^{46}$.

Cell source: Bone marrow is the preferred source of HSC. The use of cord blood is recommended only when matched unaffected siblings are available and outcomes are excellent ${ }^{47,48}$. Unrelated umbilical cord blood transplantation is usually associate with high rejection and GVHD rates and should be performed with caution ${ }^{48,49}$. 


\section{INHERITED BONE MARROW FAILURE SYNDROMES}

\section{FANCONI ANEMIA}

\section{Recommendation:}

Indications for transplant include marrow failure or clonal evolution (myelodysplastic syndrome - MDS or acute myeloid leukemia - AML). In an ideal scenario, HSCT should be performed before blood transfusions, serious infections, or the development of clonal disease ${ }^{44,50,51}$.

\section{Conditioning:}

Patient in aplasia with an identical related donor ${ }^{28}$

- Cyclophosphamide (Cy) $60 \mathrm{mg} / \mathrm{kg}$ (divided into 4 days: $\mathrm{D}-6,-5,-4,-3)$;

- Mesna, $160 \%$ of the Cy dose, divided into five doses $(0,3,6,9$, and 12 hours after Cy);

- Rabbit ATG at a dose of $5 \mathrm{mg} / \mathrm{kg}$ (divided into three days: D-3, D-2, and D-1), in patients aged 11 years and older, to reduce the incidence and severity of GVHD.

Patient in aplasia with unrelated matched donor $29,44,51$

- Cy 60 mg / kg (divided into four days: D -6, D-5, D-4, D-3);

- Mesna, $160 \%$ of the Cy dose, divided into 5 doses $(0,3,6,9$ and 12 hours after $\mathrm{Cy})$;

- Fludarabine $150 \mathrm{mg} / \mathrm{m}^{2}$ (divided into 5 days: D -6, D-5, D-4, D-3 D-2);

- Rabbit ATG $5 \mathrm{mg} / \mathrm{kg}$ (divided into three days: D -3, D-2 and D-1).

Patients progressing to MDS and/or AML with matched related or unrelated donors The preparatory regimen will depend on the clinical conditions and the disease stage. These patients may be referred for transplantation without prior chemotherapy. Patients with refractory cytopenia of MDS with less than 10\% blasts (RAEB-1) should be treated according to the recommended protocol for Fanconi's anemia in the aplastic phase. In patients with $10 \%$ or more blasts in the bone marrow and good clinical condition, the FLAG protocol (fludarabine, cytarabine, and G-CSF) is recommended, followed by related or unrelated HSCT approximately two weeks after the beginning of the chemotherapy. This scheme should be performed only on patients with a related or unrelated donor and a confirmed transplant schedule ${ }^{52}$.

GVHD prophylaxis for patients with matched related or unrelated donors should be performed with cyclosporine and a short course of methotrexate (D1 $15 \mathrm{mg} / \mathrm{m} 2, \mathrm{D}+3,+6$ and $\mathrm{D}+11: 10 \mathrm{mg} / \mathrm{m} 2)$. If possible, methotrexate can be substituted by mycophenolate mofetil $45 \mathrm{mg} / \mathrm{kg} /$ day divided into three doses. It is essential to have IV MMF available for patients unable to swallow oral MMF.

Patients in aplastic phase or with clonal evolution lacking a matched related or unrelated donor:

- It is recommended that the decision to proceed to transplant should be discussed with the experts to define the best time to perform this procedure and the best conditioning/prophylaxis regimen for GVHD.

- These patients can benefit from haploidentical transplantation using a modified dose of post-transplantation cyclophosphamide. However, we recommend that this transplant be performed only in centers with experience in this type of patient ${ }^{53}$.

\section{BLACKFAN-DIAMOND ANEMIA}

\section{Recommendation: $:^{51,54}$}

- Non-response to steroids, steroid dependency at a dose of $\geq 0.3 \mathrm{mg} / \mathrm{kg} /$ day, unacceptable steroid toxicity.

- Dependence on transfusions and/or alloimmunization.

- Pancytopenia or with progression to MDS /AML.

\section{Conditioning:}

Patients with matched related or unrelated donors $^{55}$

- Busulfan 16 - 20 mg/kg EV + Fludarabine 160 mg/ $\mathrm{m}^{2}+$ rabbit ATG $5 \mathrm{mg} / \mathrm{kg}$;

- Rabbit ATG 5 mg/kg (divided into three days: D -3, D-2 and D-1).

\section{Comments:}

Transplantation should be performed in patients under ten years of age, preferably before five years of age $^{33,55}$. The dose of busulfan should be myeloablative and based on the patient's weight and preferrable with pharmacokinetics. 
GVHD prophylaxis for patients with matched related or unrelated donors (bone marrow) should be performed with cyclosporine and a short course of meth- otrexate (D1 15mg/m2, D+3, +6 and D+11: $10 \mathrm{mg} / \mathrm{m}^{2}$ ). For patients receiving related cord blood transplants, GVHD prophylaxis performed with cyclosporine with metilprednisolone or mycophenolate mofetil.

\begin{tabular}{c|c}
\hline BODY WEIGHT & MG/KG/DAY56 \\
\hline 3 to $15 \mathrm{~kg}$ & 5.1 \\
\hline 15 to $25 \mathrm{~kg}$ & 4.9 \\
\hline 25 to $50 \mathrm{~kg}$ & 4.1 \\
\hline 50 to $75 \mathrm{~kg}$ & 3.3 \\
\hline 75 to $100 \mathrm{~kg}$ & 2.7 \\
\hline
\end{tabular}

\section{TELOMERE BIOLOGY DISEASE OR DYSKERATOSIS CONGENITA (DC)}

\section{Recommendation:}

The indication for transplant includes patients in the aplastic phase, myelodysplasia, or acute leukemia. In the ideal scenario, HSCT should be performed before transfusions, serious infections, or clonal evolution ${ }^{51}$. The prototype of telomeric biology disease (TBD) is DC; however, we recommend that transplants also be performed in patients with severe aplasia and very short telomeres $(<1 \%)$, even in the absence of classic symptoms of DC.

\section{Conditioning:}

Patients with matched related or unrelated donors $^{36,51}$

- Cy $60 \mathrm{mg} / \mathrm{kg}$ (divided into 4 days: D -6, D-5, D-4, D-3);

- Mesna $160 \%$ of the Cy dose, divided into 5 doses (0, 3, 6, 9 and 12 hours after $(y)$;

- Fludarabine $150 \mathrm{mg} / \mathrm{m}^{2}$ (divided into 5 days: D -6, D-5, D-4, D-3 D-2);

- Rabbit ATG $5 \mathrm{mg} / \mathrm{kg}$ (divided into three days: D -3, D-2 and D-1).

GVHD prophylaxis: same as in Fanconi anemia.

\section{SHWACHMAN-DIAMOND SYNDROME}

Recommendation $^{51,57}$ :

- Progressive cytopenias or pancytopenia.

- Dependence on blood transfusions.

- Progression to MDS / LMA.

\section{Conditioning:}

Patients with matched related or unrelated donors ${ }^{41,43}$

- Cy $120 \mathrm{mg} / \mathrm{kg}$ + Fludarabine $150 \mathrm{mg} / \mathrm{m}^{2}$;

- Mesna $160 \%$ of the Cy dose, divided into 5 doses $(0,3,6,9$ and 12 hours after $C y)$;

- Rabbit ATG $5 \mathrm{mg} / \mathrm{kg}$ (divided into three days: D-3, D-2 and D-1).

\section{Comments}

Although there is no consensus regarding the best conditioning for SBDS patients, the best results were obtained in patients receiving a reduced-intensity conditioning regimen using a matched related or unrelated donor ${ }^{41,43}$.

GVHD prophylaxis for patients with matched related or unrelated donors should be performed with cyclosporine and a short course of methotrexate (D1 
$15 \mathrm{mg} / \mathrm{m}^{2}, \mathrm{D}+3,+6$ and $\left.\mathrm{D}+11: 10 \mathrm{mg} / \mathrm{m}^{2}\right)$. If possible, methotrexate can be substituted by mycophenolate mofetil $45 \mathrm{mg} / \mathrm{kg} /$ day divided into three doses.

\section{CONGENITAL AMEGAKARYOCYTIC THROMBOCYTOPENIC PURPURA}

\section{Recommendation ${ }^{58,59}$}

- Severe thrombocytopenia and transfusion-dependent patients.

- Pancytopenia or evolution to MDS / AML.

\section{CONDITIONING:}

Patients with matched related or unrelated donors: 59,60

- Busulfan $16-20 \mathrm{mg} / \mathrm{kg} \mathrm{EV}$ + Fludarabine $160 \mathrm{mg} / \mathrm{m}^{2}$.

- Rabbit ATG $5 \mathrm{mg} / \mathrm{kg}$ (divided into three days: D -3, D -2 and $D-1)$.

The busulfan dose should be myeloablative and based on the patient's weight and preferrable with pharmacokinetics, as mentioned before.

GVHD prophylaxis for patients with matched related or unrelated donors (bone marrow) should be performed with cyclosporine and a short course

\section{REFERENCE}

1. Boddu PC, Kadia TM. Updates on the pathophysiology and treatment of aplastic anemia: a comprehensive review. Expert Rev Hematol. 2017;10(5):433-48.

2. Young NS, Scheinberg P, Calado RT. Aplastic anemia. Curr Opin Hematol. 2008;15(3):162-8.

3. Young NS, Kaufman DW. The epidemiology of acquired aplastic anemia. Haematologica. 2008;93(4):489-92.

4. Young NS. Current concepts in the pathophysiology and treatment of aplastic anemia. Hematology Am Soc Hematol Educ Program . 2013;2013(1):76-81.

5. Barone A, Lucarelli A, Onofrillo D, Verzegnassi $\mathrm{F}$, Bonanomi S, Cesaro S, et al. Diagnosis and management of acquired aplastic anemia in childhood. Guidelines from the Marrow Failure of methotrexate (D1 15 mg/m², D+3, +6 and D+11: $10 \mathrm{mg} / \mathrm{m}^{2}$ ). For patients receiving related or unrelated cord blood transplants, GVHD prophylaxis performed with cyclosporine with metilprednisolone or mycophenolate mofetil

\section{CONCLUSION}

HSCT is currently the only curative option for the hematological complications related to the different IBMFS $^{21,47,61}$.

All family donors should be screened before considered potential donors.

Patients and their families should be informed that HSCT corrects only the hematological manifestations of the disease.

We advise that all transplant patients be followed up for a lifetime to prevent or detect early changes resulting not only from HSCT but also from the underlying genetic disorder ${ }^{25}$.

Iron overload should be treated aggressively. Patients with $\mathrm{DC} / \mathrm{TBD}$ may have progression of the disease with pulmonary and liver fibrosis and vascular complications. Particular attention should be paid to the increased risk of cancer in all IBMFS, especially in FA, DBA, and DC 25,26 .

Study Group of the Pediatric Haemato-Oncology Italian Association (AIEOP). Blood Cells Mol Dis. 2015;55(1):40-7.

6. Hartung HD, Olson TS, Bessler M. Acquired Aplastic Anemia in Children. Pediatr Clin North Am. 2013;60(6):1311-36.

7. Shallis RM, Ahmad R, Zeidan AM. Aplastic anemia: Etiology, molecular pathogenesis, and emerging concepts. Eur J Haematol. 2018;101(6):711-20.

8. Alter BP. Bone marrow failure syndromes in children. Pediatr Clin North Am. 2002;49(5):973-88.

9. Young NS. Aplastic Anemia. N Engl J Med. 2018;379(17):1643-56.

10. Bacigalupo A. How I treat acquired aplastic anemia. Blood. 2017;129(11):10.

11. Bacigalupo A, Socié G, Hamladji RM, Aljurf M, 
Maschan A, Kyrcz-Krzemien S, et al. Current outcome of HLA identical sibling versus unrelated donor transplants in severe aplastic anemia: an EBMT analysis. Haematologica. 2015;100(5):696702.

12. Kekre N, Zhang Y, Zhang M-J, Carreras J, Ahmed $P$, Anderlini $P$, et al. Effect of antithymocyte globulin source on outcomes of bone marrow transplantation for severe aplastic anemia. Haematologica. 2017;102(7):1291-8.

13. Bacigalupo A. Alternative donor transplants for severe aplastic anemia. Hematol Am Soc Hematol Educ Program. 2018;2018(1):467-73.

14. Locatelli F, Bruno B, Zecca M, Van-Lint MT, McCann S, Arcese W, et al. Cyclosporin A and shortterm methotrexate versus cyclosporin A as graft versus host disease prophylaxis in patients with severe aplastic anemia given allogeneic bone marrow transplantation from an HLA-identical sibling: results of a GITMO/EBMT randomized trial. Blood. 2000;96(5):1690-7.

15. Scheinberg P, Young NS. How I treat acquired aplastic anemia. Blood. 2012;120(6):1185-96.

16. Groarke EM, Patel BA, Gutierrez-Rodrigues F, Rios O, Lotter J, Baldoni D, et al. Eltrombopag added to immunosuppression for children with treatment-naïve severe aplastic anaemia. $\mathrm{Br} J$ Haematol. 2021;192(3):605-14.

17. Kudo K, Muramatsu H, Narita A, Yoshida N, Kobayashi $\mathrm{R}$, Yabe $\mathrm{H}$, et al. Unrelated cord blood transplantation in aplastic anemia: is anti-thymocyte globulin indispensable for conditioning? Bone Marrow Transplant. 2017;52(12):1659-61.

18. Peffault de Latour R, Chevret S, Jubert C, Sirvent A, Galambrun C, Ruggeri A, et al. Unrelated cord blood transplantation in patients with idiopathic refractory severe aplastic anemia: a nationwide phase 2 study. Blood. 2018;132(7):750-4.

19. DeZern AE, Brodsky RA. Haploidentical Donor Bone Marrow Transplantation for Severe Aplastic Anemia. Hematol Oncol Clin North Am. 2018;32(4):629-42.

20. Arcuri LJ, Nabhan SK, Cunha R, Nichele S, Ribeiro AAF, Fernandes JF, et al. Impact of CD34 Cell Dose and Conditioning Regimen on Outcomes after Haploidentical Donor Hematopoietic Stem Cell Transplantation with Post-Transplantation Cyclophosphamide for Relapsed/ Refractory Severe Aplastic Anemia. Biol Blood
Marrow Transplant J Am Soc Blood Marrow Transplant. 2020;26(12):2311-7.

21. Dokal I, Vulliamy T. Inherited bone marrow failure syndromes. Haematologica. 2010;95(8):1236-40.

22. Alter BP. Diagnosis, Genetics, and Management of Inherited Bone Marrow Failure Syndromes. Hematology. 2007;2007(1):29-39.

23. Shimamura A, Alter BP. Pathophysiology and management of inherited bone marrow failure syndromes. Blood Rev. 2010;24(3):101-22.

24. Alter BP, Giri N, Savage SA, Rosenberg PS. Cancer in the National Cancer Institute inherited bone marrow failure syndrome cohort after fifteen years of follow-up. Haematologica. 2018;103(1):30-9.

25. Dietz AC, Savage SA, Vlachos A, Mehta PA, Bresters D, Tolar J, et al. Late Effects Screening Guidelines after Hematopoietic Cell Transplantation for Inherited Bone Marrow Failure Syndromes: Consensus Statement From the Second Pediatric Blood and Marrow Transplant Consortium International Conference on Late Effects After Pediatric HCT. Biol Blood Marrow Transplant. 2017;23(9):1422-8.

26. Bonfim C. Special pre- and posttransplant considerations in inherited bone marrow failure and hematopoietic malignancy predisposition syndromes. Hematol Am Soc Hematol Educ Program. 2020;2020(1):107-14.

27. Rageul J, Kim H. Fanconi anemia and the underlying causes of genomic instability. Environ Mol Mutagen. 2020;61(7):693-708.

28. Bonfim CM, de Medeiros CR, Bitencourt MA, Zanis-Neto J, Funke VAM, Setubal DC, et al. HLA-Matched Related Donor Hematopoietic Cell Transplantation in 43 Patients with Fanconi Anemia Conditioned with $60 \mathrm{mg} / \mathrm{kg}$ of Cyclophosphamide. Biol Blood Marrow Transplant. 2007;13(12):1455-60.

29. Bonfim C, Ribeiro L, Nichele S, Bitencourt M, Loth G, Koliski A, et al. Long-term Survival, Organ Function, and Malignancy after Hematopoietic Stem Cell Transplantation for Fanconi Anemia. Biol Blood Marrow Transplant. 2016;22(7):1257-63.

30. Ulirsch JC, Verboon JM, Kazerounian S, Guo MH, Yuan D, Ludwig LS, et al. The Genetic Landscape of Diamond-Blackfan Anemia. Am J Hum Genet. 2019;104(2):356. 
31. Darrigo Junior LG, Bomfim C. Recent Advances In Hematopoietic Stem Cell Transplantation For Inherited Bone Marrow Failure Syndromes. JBMTCT. 2020;2(1):69-76.

32. Darrigo LG, Loth G, Kuwahara C, Vieira A, Colturato $\mathrm{V}$, Rodrigues $\mathrm{AL}$, et al. Hematopoietic cell transplantation for Diamond Blackfan anemia: A report from the Pediatric Group of the Brazilian Bone Marrow Transplantation Society. Eur J Haematol. 2020;105(4):426-33.

33. Strahm B, Loewecke F, Niemeyer CM, Albert M, Ansari $\mathrm{M}$, Bader $\mathrm{P}$, et al. Favorable outcomes of hematopoietic stem cell transplantation in children and adolescents with Diamond-Blackfan anemia. Blood Adv. 2020;4(8):1760-9.

34. Calado RT, Young NS. Telomere diseases. N Engl J Med. 2009;361(24):2353-65.

35. Agarwal S. Evaluation and Management of Hematopoietic Failure in Dyskeratosis Congenita. Hematol Oncol Clin North Am. 2018;32(4):66985.

36. Fioredda F, lacobelli $S$, Korthof ET, Knol C, van Biezen A, Bresters D, et al. Outcome of haematopoietic stem cell transplantation in dyskeratosis congenita. Br J Haematol. 2018;183(1):110-8.

37. Carmem Bomfim. The 44th Annual Meeting of the European Society for Blood and Marrow Transplantation: Physicians Poster Sessions. Bone Marrow Transpl. 2019;abstract 53:145-805.

38. Ballmaier $M$, Germeshausen $M$. Advances in the understanding of congenital amegakaryocytic thrombocytopenia. $\mathrm{Br} J$ Haematol. 2009;146(1):3-16.

39. Germeshausen $M$, Ballmaier M. CAMT-MPL: Congenital Amegakaryocytic Thrombocytopenia caused by MPL mutations - Heterogeneity of a monogenic disorder - Comprehensive analysis of 56 patients. Haematologica . 2021;106(9):2439-2448.

40. Dror Y, Donadieu J, Koglmeier J, Dodge J, Toiviainen-Salo S, Makitie O, et al. Draft consensus guidelines for diagnosis and treatment of Shwachman-Diamond syndrome: Dror et al. Ann N Y Acad Sci. 2011;1242(1):40-55.

41. Myers K, Hebert K, Antin J, Boulad F, Burroughs L, Hofmann I, et al. Hematopoietic Stem Cell Transplantation for Shwachman-Diamond Syndrome. Biol Blood Marrow Transplant J Am Soc Blood Marrow Transplant. 2020;26(8):1446-51.
42. Bezzerri V, Cipolli M. Shwachman-Diamond Syndrome: Molecular Mechanisms and Current Perspectives. Mol Diagn Ther. 2019;23(2):28190.

43. Cesaro S, Pillon $M$, Sauer $M$, Smiers F, Faraci $M$, de Heredia $C D$, et al. Long-term outcome after allogeneic hematopoietic stem cell transplantation for Shwachman-Diamond syndrome: a retrospective analysis and a review of the literature by the Severe Aplastic Anemia Working Party of the European Society for Blood and Marrow Transplantation (SAAWP-EBMT). Bone Marrow Transplant. 2020;55(9):1796-809.

44. Dufour C. How I manage patients with Fanconi anaemia. Br J Haematol. 2017;178(1):32-47.

45. Horan J, Wang T, Haagenson M, Spellman SR, Dehn J, Eapen M, et al. Evaluation of HLA matching in unrelated hematopoietic stem cell transplantation for nonmalignant disorders. Blood. 2012;120(14):2918-24.

46. Petersdorf EW, Bengtsson M, De Santis D, Dubois $\mathrm{V}$, Fleischhauer $\mathrm{K}$, Gooley $\mathrm{T}$, et al. Role of HLA-DP Expression in Graft-Versus-Host Disease After Unrelated Donor Transplantation. J Clin Oncol Off J Am Soc Clin Oncol. 2020;38(24):2712-8.

47. Dokal I, Vulliamy T. Inherited aplastic anaemias/ bone marrow failure syndromes. Blood Rev. 2008;22(3):141-53.

48. Bizzetto R, Bonfim C, Rocha V, Socie G, Locatelli $F$, Chan K, et al. Outcomes after related and unrelated umbilical cord blood transplantation for hereditary bone marrow failure syndromes other than Fanconi anemia. Haematologica. 2011;96(1):134-41.

49. Pagliuca S, Ruggeri A, Peffault de Latour R. Cord blood transplantation for bone marrow failure syndromes: state of art. Stem Cell Investig. 2019;6:39.

50. Peffault de Latour R, Soulier J. How I treat MDS and AML in Fanconi anemia. Blood. 2016;127(24):2971-9.

51. Dalle J-H, de Latour RP. Allogeneic hematopoietic stem cell transplantation for inherited bone marrow failure syndromes. Int J Hematol. 2016;103(4):373-9.

52. Debureaux $P E$, Sicre de Fontbrune $F$, Bonfim C, Dalle JH, Buchbinder N, Bertrand Y, et al. FLAG-sequential regimen followed by bone marrow transplantation for myelodysplastic 
syndrome or acute leukemia in patients with Fanconi anemia: a Franco-Brazilian study. Bone Marrow Transplant. 2021;56(1):285-288.

53. Bonfim C, Ribeiro L, Nichele S, Loth G, Bitencourt M, Koliski A, et al. Haploidentical Bone Marrow Transplantation with Post-Transplant Cyclophosphamide for Children and Adolescents with Fanconi Anemia. Biol Blood Marrow Transplant. 2017;23(2):310-7.

54. Bartels $M$, Bierings $M$. How I manage children with Diamond-Blackfan anaemia. Br J Haematol. 2019;184(2):123-33.

55. Darrigo LG, Loth G, Kuwahara C, Vieira A, Colturato $V$, Rodrigues $A L$, et al. Hematopoietic cell transplantation for Diamond Blackfan anemia: A report from the Pediatric Group of the Brazilian Bone Marrow Transplantation Society. Eur J Haematol . 2020;105(4):426-433.

56. Bartelink IH, Boelens JJ, Bredius RGM, Egberts ACG, Wang C, Bierings MB, et al. Body weight-dependent pharmacokinetics of busulfan in paediatric haematopoietic stem cell transplantation patients: towards individualized dosing. Clin Pharmacokinet. 2012;51(5):331-45.

57. Cesaro S, Pillon M, Sauer M, Smiers F, Faraci M, de Heredia $C D$, et al. Long-term outcome after allogeneic hematopoietic stem cell transplantation for Shwachman-Diamond syndrome: a retrospective analysis and a review of the literature by the Severe Aplastic Anemia Working Party of the European Society for Blood and Marrow Transplantation (SAAWP-EBMT). Bone Marrow Transplant . 2020;55(9):1796-1809.

58. Ballmaier M, Germeshausen M. Congenital Amegakaryocytic Thrombocytopenia: Clinical Presentation, Diagnosis, and Treatment. Semin Thromb Hemost. 2011;37(06):673-81.

59. Al-Ahmari A, Ayas M, Al-Jefri A, Al-Mahr M, Rifai $\mathrm{S}$, Solh HE. Allogeneic stem cell transplantation for patients with congenital amegakaryocytic thrombocytopenia (CAT). Bone Marrow Transplant. 2004;33(8):829-31.

60. Mahadeo KM, Tewari P, Parikh SH, Driscoll TA, Page $K$, Martin $P L$, et al. Durable engraftment and correction of hematological abnormalities in children with congenital amegakaryocytic thrombocytopenia following myeloablative umbilical cord blood transplantation. Pediatr Transplant. 2015;19(7):753-7.

61. Alter BP. Inherited bone marrow failure syndromes: considerations pre- and posttransplant. Blood. 2017;130(21):2257-64. 